\title{
Д.В. Карась
}

Научно-исследовательский институт комплексных проблем сердечно-сосудистых заболеваний (Кемерово, Россия)

\section{Теоретико-методологические подходы к пониманию интернальности как психологического феномена}

\begin{abstract}
Проанализированы представления о феномене интернальности. Интернальность раскрыта как интегральная личностная характеристика своеобразия протекания психологических феноменов, конституирующих процессы активного порождения неопределенности и её субъектного, интенционального и ответственного разрешения при осуществлении личностного выбора. Поставлены проблемные вопросы о двух уровнях реализачии интернального поведения: направленности на субъектное отношение к реальности и личностной компетенции, позволяющей реализовать эту направленность в различных жизненных ситуачияхх.

Ключевые слова: личность; интернальность; локус контроля; личностный выбор; неопределенность; субъектность; ответственность; самодетерминаиия; суверенность; личностная регуляция поведения.
\end{abstract}

Одной из центральных в психологии личности является проблематика источников детерминации поведения - в какой мере то, что выбирает и делает человек, определяется факторами разной природы и в какой мере сам человек способен управлять этими факторами, а значит, своим поведением и жизнью. С позиций философии это вопросы о существовании, границах, способах осуществления и цене человеческой свободы.

Многообразие психологических подходов к решению этих вопросов непосредственно сопряжено с многообразием представлений о личности и человеке, осуществляющем выбор. Однако вне зависимости от разночтений в понимании того, что такое личность, на современном этапе развития психологии едва ли можно найти подход, где в какой-либо форме не принималось бы детально разработанное Л.С. Выготским положение, что сущностной психологической характеристикой личности является овладение собственным поведением [1]. Разработка тематики психологических механизмов и принципов участия человека (наряду с природой и культурой) в создании условий, обстоятельств и событий его жизни, возможностей собственных сознательных усилий, становления соответствующих качеств и способностей - одна из ключевых предметных областей психологической персонологии.

Среди множества конструктов, посредством которых разрабатывается психологическая теория собственной активности человека, одним из 
наиболее востребованных в настоящее время является понятие «интернальность». Оно применяется как характеристика в отношении различных психологических реалий - интернальность субъективного контроля, интернальность ценностей и смыслов, интернальность каузальных ориентаций, интернальность мотивации и др. Понятием «интернальность» психологи в основном характеризуют психологические феномены регуляции поведения человека в ситуациях, требующих принятия решений, но также применяют его и в отношении личности в целом.

Интернальность в общем случае указывает на то, что причина и источник активности при реализации некоторого психологического процесса или акта (выбора, действия, поведения), ключевые регулирующие влияния и контроль происходящего принадлежат собственной активности человека как субъекта. Будучи психологическим понятием интернальность не просто описательно характеризует соответствующие феномены, но и указывает на психологию процессов и механизмов, реализуя которые человек овладевает собой и своим поведением, - психологию интернальности, интернального поведения, интернального выбора.

Цель данной статьи - раскрыть основные теоретико-методологические подходы к пониманию интернальности и сформулировать проблемные вопросы относительно теоретического осмысления этого феномена.

Интернальность - это конструкт, исторически связанный с категорией «локус контроля», введенной в научный оборот Дж. Роттером в теории социального научения. Он рассматривает локус контроля как важнейший субъектный фактор поведения в ситуации, требующей осуществления выбора, как степень понимания человеком причинных взаимосвязей между собственным поведением и достижением желаемого [2].

Дж. Роттер показал, что человек во взаимодействии с окружающим миром приобретает обобщенный опыт, особый тип обобщенных ожиданий о контроле возникновения поведенческих подкреплений в результате успешных или неуспешных действий. Если человек ожидает, что подкрепления зависят от его собственного поведения, то говорят об интернальном локусе контроля, если ожидает контроля подкреплений силами извне - об экстернальном. Согласно Дж. Роттеру, локус контроля не является врожденной и неизменной личностной чертой. Конструкт следует рассматривать как континуум экстернальность-интернальность, и убеждения людей в отношении различных сфер жизни могут быть расположены на всех точках между полюсами.

Понятие локуса контроля органично вписалось в методологически близкий контекст концепций реципрокного детерминизма и каузальной атрибуции. Так, А. Бандура, отводя значимую роль когнитивным процессам в опосредовании связи между стимулом и реакцией, вводит в модель реципрокного детерминизма понятие «самоподкрепление». Он обнаружил, что подкрепление, осуществляемое самим субъектом, оказывается эффективнее подкреплений от внешней среды; в результате самоудовлетворения от достижения целей у человека появляется специфический мотив прила- 
гать больше усилий в желаемом направлении, а уровень внутренней мотивации человека обычно связан с типом и ценностью побуждений [3].

В свою очередь, Ф. Хайдер даёт понятие о локусе каузальности, который выражает ситуативное или устойчивое осознание человеком в качестве причины наступления того или иного события собственное поведение или внешние средовые обстоятельства. Подобным образом интернальность понимал Б. Вайнер при исследовании мотивации достижения успеха и избегания неудач. Согласно Б. Вайнеру, люди с высокой (результирующей) мотивацией достижения интернальны в том смысле, что воспринимают успех как связанный с собственными способностями и усилиями, а неудачу - как вызванную недостатком усилий [4].

Таким образом, А. Бандура, Ф. Хайдер и Б. Вайнер подтверждают статус локализации разных аспектов контроля в качестве реально влияющего на поведение человека фактора субъективного отношения к ответственности за происходящие события.

В классике психологической литературы встречается представление об ещё одном аспекте интернальности, не связанном с концепцией локуса контроля и рассматривающемся в трудах Д. Рисмена как личностная характеристика ценностного сознания, выраженная в представлении о «локусе ценностей» в контексте различных типов социального характера [5]. Д. Рисмен рассматривал локус ценностей с позиции - заложены ли ценности в самом индивиде или принадлежат другим. Поведение людей, «ориентированных изнутри», регулируется внутренними интернализованными целями и ценностями, а людей, «ориентированных извне», - ценностями внешними. М.С. Яницкий замечает, что, «по мнению К. Муздыбаева, различие между концепциями Д. Рисмена и Дж. Роттера состоит в том, что первый имеет дело с механизмами социального контроля, а второй - индивидуального... Оба типа социального характера Д. Рисмена вполне могут быть контролируемы как интернально, так и экстернально» [6. С. 93]. Тем не менее представление о социальном характере ценностно «ориентированной изнутри» личности - существенный аспект интернальности, поскольку свидетельствует о значимости проявления способности человека к внутренней ценностной опоре и внутренне мотивированному поведению, причем в масштабах массового сознания.

Положение Дж. Роттера о том, что локализация контроля относительно различных сфер жизни неоднородна, и соответствующие убеждения могут быть расположены в континууме интернальность-экстернальность, нашло отражение в представлениях о структуре локуса контроля. Один из распространенных в отечественной психологии диагностических инструментов для измерения «уровня субъективного контроля» позволяет фиксировать как общую интернальность, так и интернальность в различных сферах жизни: в области достижений, неудач, в производственных, семейных и межличностных отношениях, а также в отношении здоровья и болезни [7]. Однако, на наш взгляд, вопрос о генезе интернальности в различных сферах жизни на сегодняшний день ещё не вполне осмыс- 
лен, что связано с дискуссионным характером и разночтениями в понимании самого этого феномена.

Обобщая изложенные взгляды, можно заключить, что интернальность даже в классическом представлении содержательно неоднородна, и аспект локуса контроля как обобщенного опыта контроля подкреплений является только одним из её проявлений. К другим аспектам интернальности следует отнести локус каузальности как тенденцию воспринимать в качестве причин событий собственную активность и усилия (Ф. Хайдер, Б. Вайнер), феномен способности к самоподкреплению (А. Бандура), а также тенденцию принимать решения и действовать с опорой на внутренние ценностные и мотивационные ориентиры (Б. Вайнер, Д. Рисмен).

А.А. Бодалёв отмечает, что «введение в психологию понятия локуса контроля стимулировало огромное количество исследований этого феномена, поток которых продолжает нарастать и в настоящее время» [8. С. 400].

Само понятие интернальности как полюса локуса контроля первоначально имеет смысл в контексте когнитивно-бихевиоральных теорий социального научения и каузальной атрибуции. Психологи включают его в разнообразные теоретические контексты и эмпирические модели. Приведем некоторые характерные примеры, расширяющие представление об интернальности и свидетельствующие о широте взаимосвязей этого качества с другими значимыми психологическими и личностными параметрами.

Первоначальное представление о локализации субъективного контроля было развито в концепцию локуса каузальности в теории автономии личности Э. Деси и Р. Райана. Воспринимаемый локус каузальности определяется авторами как когнитивный конструкт, представляющий и выражающий степень, с которой человек является самодетерминированным при планировании и осуществлении какого-либо поведения. «Самодетерминацией называется способность выбирать и иметь выбор» [9. С. 104].

Принципиальным отличием локуса каузальности от классического понимания локуса контроля (где интернальность формируется исключительно как результат прагматического обобщения опыта поведения) является положение о базовой потребности, неразрывно связанной с волевыми качествами человека и лежащей в основе внутренне мотивированной активности и развития личности. Самодетерминированным авторы называют поведение, направленное на достижение мотивирующего переживания автономии и компетентности - видов удовлетворенности соответствующих базовых личностных потребностей.

Локус каузальности может быть интернальным и экстернальным. Отличия между ними - в особенностях восприятия человеком событий как информационных или контролирующих. Информационное событие актуализирует потребность в автономии и порождает внутреннюю субъектную активность по формированию интернальной смысловой причины дальнейшего поведения, осуществления интернального выбора. Восприятие события контролирующим основывается на потребности в контроле и само, являясь причиной, экстернально задаёт направление выбора. «Внутренние 
информационные события усиливают самодетерминированное функционирование и повышают внутреннюю мотивацию. Внутренние контролирующие события переживаются как давление с целью получения специфического результата и подрывают внутреннюю мотивацию» [9. С. 110]. Такое представление хорошо согласуется с традиционными для отечественной психологии идеями (берущими начало в учении о высших психических функциях) о развитии личности как становлении процессов опосредствования поведения интернальными (интериоризованными) психологическими средствами и развитии механизма автостимуляции [10], хотя представления о движущих силах и механизмах формирования «автономного» поведения существенно разнятся.

Так, положение о существовании базовой личностной потребности в автономии, актуализация которой обусловливает интернальное поведение, имеет характер аксиоматического допущения, сделанного на основе обобщения наблюдений за «стремлением индивидов к развитию своих интересов и способностей» [Там же. С. 106]. Авторы теории самодетерминации не приводят достаточных естественнонаучных оснований и развернутого теоретического осмысления природы данной потребности, разъясняется лишь, что она врожденная, а способность к её актуализации зависит от опыта открытого свободного поведения в раннем возрасте и от релевантных особенностей социальной среды. «Рост внутренней мотивации, обеспечивающий оптимальное развитие личности, зависит от социальных условий, которые поддерживают и охраняют автономию человека или же наоборот, разрушают ее» [9. С. 107]. Однако сама идея, что в основе самодетерминации лежит натуральное общее основание, по нашему мнению, требует пристального внимания, и мы более подробно остановимся на этом вопросе в дальнейшем.

Связь локуса контроля с верой в свои силы и способности исследовали Р. Вулри и Дж. Роттер, Д. Уотсон и Э. Боумел. Они показали, что в ситуации, требующей принятия решения на основе собственных навыков, не зависящих от случая и ситуации, интерналы делают меньше ошибок, чем экстерналы, а ситуация неопределенности дезорганизует их в меньшей степени. Вместе с тем ценность ситуации «шанса» для экстерналов выше, чем для интерналов [11]. Это означает, что общая интернальность, помимо прочего, является основой своеобразной личностной компетенции, позволяющей человеку эффективно оперировать собственными психологическими ресурсами в различных ситуациях, требующих принятия решения.

Г. Бир показал, что люди с когнитивно сложным контролем поведения устойчиво показывают признаки интернальности. Это выражается в высоком количестве степеней свободы, социальной пластичности и независимости от «поля», в высокой дифференциации восприятия, способности к разграничению эмоциональных и интеллектуальных оценок, в высокой абстрагированности мышления, произвольности в глубине семантической обработки, в учете значительного объема невербальной информации и осознании собственных качеств, а также в способности к высокой эмпа- 
тии и пониманию мотивов другого человека [12]. Очевидно, что интернальность не тождественна когнитивной сложности, однако данные наблюдения свидетельствует о большей способности к осознанному и смысловому поведению интерналов. Подобные выводы были сделаны А.В. Серым в контексте исследования психологических особенностей (включая когнитивную сложность) функционирования системы личностных смыслов при различных актуальных смысловых состояниях, в структуре которых интернальность является одним из предикторов смысловой продуктивности [13].

Ряд исследований посвящен связи локуса контроля и особенностей структуры и содержания субъективной временной перспективы. Так, исследования Ф.У. Вессмана, С. Тайера и Д.С. Гормана показали, что интерналы в своих временных перспективах более ориентированы на будущее, лучше способны концептуализировать отрезки времени. По сравнению с экстерналами их временная перспектива охватывает более дальнюю зону как будущего, так и прошлого, причем независимо от характера событий, в то время как временная перспектива экстерналов укорочена и малособытийна [14]. О связи интернальности и общей компетентности во времени свидетельствуют данные Д.А. Леонтьева [15], Е.М. Вечкановой [16]. Последняя сообщает также, что обусловленность временной перспективы локусом контроля возрастает в период переживания кризиса идентичности, а значит, интернальность способствует конструктивному отношению к неопределенности как внешней, так и внутренней ситуации.

Есть данные об обратной связи интернальности и тенденции к аддиктивному поведению [17]. Интернальность является значимым личностным фактором стрессоустойчивости и эффективного совладания с кризисными жизненными ситуациями, она снижает вероятность развития эмоциональных нарушений, в том числе ввиду проявления сопряженной с интернальностью способности опосредствовать эмоциональные реакции смысловыми средствами, более открыто и активно вести себя в проблемных ситуациях [16, 18-21].

Зафиксирована также связь интернальности и общей социальной эффективности, включая уровень материальной обеспеченности [22]. По данным А.А. Реана, интернальность связана с уровнем профессионального мастерства [21], что косвенно свидетельствует о деятельностной природе становления интернальности. В целом можно заключить, что поведение интернального типа, кроме прочего, предполагает определенный уровень владения личностными навыками опосредствования, некоторую практически наработанную личностную компетенцию по управлению собственным поведением.

Н.Т. Физер показал, что удовлетворенность вознаграждением за решение задачи у интерналов растет пропорционально оценке собственного вклада в её решение, ценность вознаграждения зависит от интернальности поведения [23]. Более того, по данным Б. Вайнера (1974), если локус контроля воспринимается как внешний, результат собственных действий во- 
обще не оказывает на индивида выраженного эмоционального воздействия, т.е. человек остаётся безучастным к происходящему [24. С. 273]. Ценность результатов собственной активности, характерное для интерналов отношение к собственным усилиям и их результатам как к личностной значимости означают не что иное, как ответственность. Следует отметить традиционность понимания интернальности через призму категории «ответственность». Уже в теории каузальной атрибуции интернальность понимается прежде всего как тенденция приписывать ответственность за события внутренним причинам.

М.С. Яницкий характеризует уровень интернальности как «степень независимости и самостоятельности человека в достижении своих целей, развития чувства личной ответственности за происходящие с ним события» [6. С. 93]. К. Муздыбаев определяет ответственность как волевое личностное качество, проявляющееся в субъективном контроле над собственной деятельностью [25]. Уровень субъективного контроля непосредственно свидетельствует об уровне принятии человеком на себя ответственности за события в своей жизни.

По замечанию М.С. Яницкого, общий уровень принятия ответственности также «может соответствовать уровню внутреннего личностного принятия, интернализованности ценностных представлений» [6. С. 93]. Соответственно, формирование интернальности может быть рассмотрено как процесс личностного осмысления соответствующих ценностных представлений и принятия человеком ответственного решения относительно приоритета значимости одних ценностей по отношению к другим. Речь идёт о процессе интернализации, который определяется А.В. Серым (на основе работ В. Грулиха, Я. Гудечека) как процесс сознательного и активного восприятия окружающего мира на основе воспроизводства принятых на определенном смысловом уровне норм и ценностей. Интернализация предполагает ответственную позицию субъекта, интерпретирующего события своей жизни как результат собственной деятельности [13. С. 24-25]. Основным продуктом интернализации является формирование интернальности как способности автономно порождать и актуализировать ценностно-смысловые причины для собственной активности [26. С. 180].

Необходимо подчеркнуть, что интернальная локализация контроля, обобщенная личностная ориентация на восприятие жизненных событий как результатов собственных действий и вытекающее из такого ожидания чувство ответственности не всегда являются психологически благоприятными обстоятельствами. А.А. Реан указывает: «Субъект, который перманентно и тотально берет на себя ответственность за все неудачи, провалы, промахи в жизни, подвержен серьезному риску дезадаптации. Такая ориентация на всеобъемлющую ответственность в случае серьезности или множественности неудач является основательной почвой для возникновения комплекса вины... является фактором риска психоэмоциональной дезадаптации, роста дискомфорта, напряжения» [27. С. 109]. Об этом же пишет и Р.М. Шамионов: «...в наших исследованиях субъективного контроля 
было показано, что в случае его избыточности в сфере неудач, например, ярко выражена неудовлетворенность собой» [28. С. 48].

С другой стороны, Р.М. Шамионов отмечает, что «социум в ряде случаев в качестве нормы транслирует установку на неудовлетворенность при принятии ответственности на себя за свои ошибки и неудачи, в противном случае (экстернальность), напротив, выявляется удовлетворенность собой. На наш взгляд, в этом проявляется навязывание ответственности за неуспех, неудачи самому субъекту, а за достижения - внешним факторам...» [Там же. С. 48]. Таким образом, автор отмечает существенный характер влияния социокультурных факторов на психологическую результативность практики интернального поведения. Это наблюдение подтверждается зарегистрированной еще Дж. Роттером определенной сложностью взаимосвязи интернальной локализации контроля и когнитивных функций в зависимости от социокультурной ситуации. По данным Дж. Роттера и И. Бэттла (1963), локус контроля чернокожих североамериканских детей, живущих в неблагоприятных социоэкономических условиях, обладает определенной спецификой: «...дети с внешним локусом контроля обычно имеют более высокий IQ, чем дети с внутренним локусом контроля» [24. С. 380], в то время как традиционно считается, что более низкие уровни IQ соответствуют экстернальной направленности [29. С. 27].

Д. Мацумото в книге «Психология и культура» [30] также отмечает, что феномены, связанные с интернальностью, имеют культурную специфику; в частности, установка на самоэффективность, автономию и личный контроль (Я контролирую окружение) характерна для жителей Северной Америки, а установка на гармоничные отношения с социальным и физическим окружением - для жителей Восточной Азии (окружение контролирует меня). Однако и первый и второй подходы взаимодействия с окружающим миром обеспечиваются специфическими психологическими механизмами, которые позволяют субъекту сохранять и психическое здоровье, и психологическое благополучие. В основе этих различных подходов лежат, по Д. Мацумото, различия в ценностных ориентациях.

Таким образом, высокая интернальность не всегда является фактором эффективности поведения и деятельности, но в определенных социальных ситуациях может вести к дезадаптивным проявлениям. Оптимальная структура локусов интернальности может быть ситуационно и культурно специфичной, формирующейся при тесном взаимодействии человека со средой и опосредованной различными социокультурными переменными.

В качестве способа учесть сложность взаимосвязей интернальности, адаптивности и социокультурной ситуации А.А. Реан ввел модель «хорошего» интернального контроля, при котором ответственность за причины неудач связана с экстернальными факторами, а ответственность за преодоление неудач - с интернальными. Данная модель «...позволяет субъекту сохранить уверенность в себе, активную позицию и чувство контроля за событиями своей жизни, не приобретая попутно чувства всеобъемлющей 
вины и эмоциональной дезадаптации» [27. С. 109]. Такая модель является одним из возможных способов сохранения личностной стабильности при переживании жизненных трудностей. Однако практика «хорошего интернального контроля» может способствовать дезинтеграции жизненного опыта, делению событий на «хорошие» и «плохие», несколько искусственному отделению себя от одних событий и соединению с другими, что может ограничивать возможности человека по дальнейшему развитию способности к «овладению собственным поведением», стагнации в этом отношении.

На наш взгляд, при интерпретации обнаруженных корреляций между выраженной интернальностью локализации контроля, риском психоэмоциональной дезадаптации и снижением когнитивных функций в специфических социокультурных условиях следует обратить внимание, что рассматриваемые понятия «локус контроля», «ответственность» и «интернальность» методологически не тождественны. Классические исследования локуса контроля проводились в рамках когнитивно-бихевиоральной традиции, где категория ответственности представлена в нейрофизиологическом ключе, за ней не стоит психологически системного цельноличностного содержания; кроме того, в базовой методологии бихевиоризма не принимаются во внимание принципиальные положения относительно психологических закономерностей сознательной и бессознательной личностной регуляции эмоциональных состояний, разработанные при изучении феноменов психологической защиты, совладающего (копинг) поведения и организующего потенциала смысложизненных ориентаций. Не учитываются также культурно-исторические закономерности развития высших психических функций и в целом фундаментальные аспекты смысловой организации личностных процессов.

Говоря об ответственности, отметим, что эта категория понимается нами как один из центральных конструктов экзистенциальногуманисти-ческой психологии, как изначально присущая человеку в том смысле, что принципиально «человек ответствен за то, что он есть» [31. C. 326]. Независимо от осознания этого факта сущность человека определяется его собственными действиями, постоянно осуществляемым выбором самого себя. Следовательно, принятие ответственности - это готовность «осознавать творение самим собой своего «я», способность осуществлять осознанный выбор и признавать собственное авторство» [32. С. 245], готовность принимать последствия совершенного выбора, какими бы они ни были [33]. С этого ракурса интернальность не тождественна ответственности, но является её предиктором как особое интенциональное (см. постнеклассическую интерпретацию этого понятия [34]) состояние сознания и сам способ «авторского», субъектного отношения человека к себе и жизненным событиям. Так или иначе, теоретическая связь локализации контроля с ответственностью как личностным качеством обоснована и подтверждена многими эмпирическими исследованиями (например, [25, 35-37]). 
Если вернуться к положению Дж. Роттера о вариабельности локализации контроля в отношении различных сфер жизни, т.е. учесть, что обобщенные ожидания и фактические возможности контроля человеком жизненных событий и обстоятельств могут существенно отличаться в разных сферах жизни (в границах условного континуума интернальныйэкстернальный), и методологически транспонировать это положение, охарактеризовав интернальность как постоянно и закономерно развивающуюся способность человека к субъектно-деятельностному обращению со всевозможными реалиями его жизненного мира, т.е. как интегральную высшую психическую функцию «по овладению собственным поведением» (к которой в таком случае полностью применима культурно-историческая логика интериоризации при развитии ВПФ), то окажется допустимым и необходимым следующее предположение. Вероятно, следует говорить о нескольких уровнях становления и реализации интернальности в зависимости от природы (физическая, социальная, психоэмоциональная, психологическая, духовная) и смысловой сложности (включая аспект временной организации смысловой реальности) осваиваемых явлений. Тогда становится понятным, что способность удерживать понимание связей между собственными действиями и их результатами на физическом плане не обязательно сопряжена с развитой способностью осознавать связи и проявлять субъектную осмысленную активность при обращении с явлениями психологического или духовного плана. Проявление человеком способности к интернальному обращению с событиями и обстоятельствами социального плана (социальные успехи или неудачи, освоение социокультурных норм и ценностей) не свидетельствует непосредственно о способности сохранять субъектность и поведенческую эффективность при обращении с собственными эмоциями, в том числе субъективно тяжелыми. Эмоциональные состояния хотя и сопряжены с событиями на социальном и других планах, сами потенциально являются предметами субъектного обращения, что требует специфических компетенций.

Об интернальности человека в отношении собственных эмоций может свидетельствовать, как показывают исследования, в том числе и наши, выраженная опосредствованность эмоциональных реакций смысловыми процессами, что проявляется в низком уровне напряженности системы психологических защит [38, 39] и невысоком уровне эмоциональной чувствительности к социальному отвержению при выраженной осмысленности жизни у психологически здоровых людей [40].

Каждый уровень становления интернальности, каждый план приложения субъектной активности требует от человека специфических компетенций, образования и опыта, нарабатываемых от внешних форм поведения к внутренним и от простых явлений к психологически сложным. Следовательно, можно говорить о принципиальной возможности постепенного уровневого расширения границ интернального взаимодействия при психологическом освоении человеком многомерного жизненного мира. Причем базовый принцип интернального взаимодействия с реалиями жизненного 
мира постоянен: осознание причинно-следственных связей между явлениями различной природы и собственным поведением и устремленность человека к реализации возможностей воздействовать на условия возникновения этих явлений.

Таким образом, мы делаем заключение, что интернальность реализуется в цельно-личностном опосредствовании поведения и отношений в различных сферах жизни, основанном на сложных и нелинейных по своей природе психологических процессах, а основными психологическими признаками интернальности являются субъектность, интенциональность и ответственность.

В контексте нашего исследования имеет значение, что интернальность является прежде всего фактором, регулирующим качественное своеобразие внутреннего и внешнего поведения человека в ситуации, требующей осуществления выбора, как специфический психологический принцип - императив сохранения субъектности в ситуации неопределенности. В этом отношении Д.А. Леонтьев показывает, что локус контроля существенным образом влияет на протекание деятельности по осуществлению личностного выбора в ситуации неопределенности. Интернальность влияет на скорость конструирования оснований и смысловых критериев для сопоставления имеющихся альтернатив и осуществление этого сопоставления, а также на общую эффективность внутренней деятельности выбора [15]. А.А. Бодалёв также сообщает, что «интерналы более последовательны и продуктивны в ситуациях принятия решения и ситуациях, связанных с риском... они проявляют большую когнитивную активность, чем экстерналы» [8. С. 400].

Следует обратить внимание на сопряженность локализации контроля и способности к осмысленному, а значит, субъектному и интенциональному поведению.

Согласно Д.А. Леонтьеву, интернальность (как убежденность человека в своей способности контролировать жизненные события и вера в способность осуществлять собственный выбор) тесно связана, во-первых, с телеологичностью как наиболее общей смысловой ориентацией (склонность вообще ориентироваться на смысл своих действий, а не на их причину, ставя по отношению к ним вопрос «для чего» в противовес вопросу «почему» [39. С. 292]). Во-вторых, интернальность проявляется в способности человека осознавать и реализовывать себя как активного субъекта жизни, что обобщено в понятии «действенная жизненная позиция» [41. С. 38-39]. В-третьих, интернальность коррелирует с общей осмысленностью жизни как «количественной мерой степени и устойчивости направленности жизнедеятельности субъекта на какой-то смысл» [39. С. 293]. В этой связи Д.А. Леонтьев отмечает, что «субъективное переживание наличия смысла жизни, как правило, связано с осознанием ответственности за результаты своей деятельности» [Там же. С. 309].

Четвертым аспектом смысловой регуляции поведения Д.А. Леонтьев предлагает дихотомию: ориентация на ценности или на потребности в ка- 
честве источника смыслообразования. Здесь уместно замечание А.А. Бодалева, что интерналы «проявляют большую готовность отсрочить сиюминутное, легкодоступное удовольствие ради достижения отдаленного, но более ценного блага» [8. С. 400]. А Д.А. Леонтьев поясняет, что «человек с доминирующей потребностной регуляцией будет в большей мере подчинять поведение своим сиюминутным желаниям, будет... мало учитывать отдаленные последствия своих поступков и решений» [39. С. 296]. Так интернальность раскрывается как тенденция к проактивному поведению, как противоположность реактивного.

Пятый аспект смысловой регуляции - временная локализация ведущих смысловых ориентиров - также связан с локусом контроля. По заключению А.В. Серого, основанному на результатах эмпирического исследования, «осмысленность прошлого, настоящего и будущего даёт человеку убежденность в том, что ему дано контролировать свою жизнь, принимать ответственность за происходящие в ней события и воплощать принятые решения» [13. С. 66]. Причем интернальность значимо возрастает до среднего уровня при высокой осмысленности по меньшей мере двух из трех временных модусов локализации смысла (в ряду прошлое, настоящее, будущее) какой-либо ситуации или жизни в целом и наиболее высока при высокой осмысленности всей временной перспективы [Там же. С. 63]. Иначе говоря, способность актуализировать личностный смысл в ситуации неопределенности, способность осуществлять интернальный выбор [Там же. С. 152-175] - продуктивность актуального смыслового состояния [38] - необходимо сопряжены с выраженной интернальностью.

Ещё в 2000 г. А.А. Бодалёв отмечал, что эмпирические исследования локуса контроля свидетельствуют о значительном влиянии этого фактора на многообразные характеристики психики и поведения, что эта категория отражает переживание субъектом «его связанности или несвязанности с событиями собственной жизни», при этом налицо «недостаточная теоретическая разработанность» этой проблемы [8. С. 402-403].

При обобщении рассмотренных представлений мы приходим к заключению, что интернальный локус контроля в его классическом понимании - это только одно из проявлений интернальности как более глубокого и существенного психологического качества. Люди с внутренней и внешней локализацией субъективного контроля, равно как интерналы и экстерналы в более широком понимании, качественно своеобразно взаимодействуют с миром и имеют ряд характерных психологических и личностных различий.

Несмотря на многоаспектность индивидуальных различий между интерналами и экстерналами, корень их усматривается в своеобразии подхода к осуществлению выбора в требующих того ситуациях и в своеобразии исходного отношения к ситуациям неопределенности. Т.В. Корнилова отмечает: «...при любом выборе в ситуации неопределенности человеку приходится ставить перед собой вопросы, которые можно объединить в общей формулировке «Какой я?»... Принятие личностной цены выбора означает и самоопределение в вопросе «Кто я?», или «Каким я себя вижу 
(хотел бы видеть)?». От ответа на эти вопросы зависит актуализация тех или иных психологических особенностей в стратегиях подготовки выбора» [42. С. 75-76]. Мы делаем вывод, что для «интерналов» эти вопросы являются устойчиво актуальными (безотносительно их представленности на уровне сознания), это проявляется как способность человека осуществлять выбор, сохраняя субъектность, интенциональность и чувство ответственности, в отличие от экстерналов, для которых ценность субъектности в ситуации выбора, по-видимому, не является мотивирующей и не реализуется.

Определение субъектности, интенциональности и ответственности при взаимодействии с миром в качестве состояний, реализующих «связность человека с событиями собственной жизни», с высокой вероятностью указывает на имманентную связь феномена интернальности с ядерными личностными измерениями и соответствующими движущими силами, актуализация которых позволяет человеку «обрабатывать» ситуацию выбора на верхних личностных уровнях (представление о личностных уровнях регуляции выбора сформировано в контексте развития смысловой теории мышления, например [43]).

Таким образом, правомерно поставить проблемный вопрос об идентификации и теоретическом осмыслении базовой динамической силы, проявляющейся как тенденция к интернальному поведению и лежащей у основания становления соответствующих навыков и качеств. Иными словами, какую потребность реализует человек, осуществляя интернальное поведение? По какой причине субъектность имеет фактически переживаемую и практически реализуемую личностную ценность? По какой причине интернальность оказывается взаимосвязанной, как показано выше, с таким обширным кругом важнейших личностных качеств и параметров? Мы предполагаем, что от ответа на данные вопросы зависит понимание механизма интернального поведения и генеза интернальности.

Мы считаем целесообразным рассмотреть понятие интернальности не как механистическую категорию когнитивно-бихевиорального дискурса, а в общепсихологическом ключе в широком контексте проблематики произвольности и избирательности психики, личностной опосредствованности психических процессов и поведения, требующего осуществления выбора.

Выбор, в каком бы контексте и на каком бы уровне он ни осуществлялся, это всегда поведенческий акт, которым человек непосредственно проявляет себя в мире, это личностно-уникальным образом «направленное взаимодействие» [44. С. 16], а качество выбора (интернальный-экстернальный) свидетельствует о качестве связи человека как субъекта жизни с действительностью, представленной для человека в элементах психологической структуры актуальной ситуации выбора. Соответственно, вопросы относительно психологии интернальности целесообразно рассматривать в контексте представлений о человеке, осуществляющем личностный выбор.

Суть ситуации выбора - это всегда состояние неустойчивости, неопределенности, на что указывают многие авторы (Т.В. Корнилова, 
Д.А. Леонтьев, В.П. Зинченко, С. Мадди, Е.Т. Соколова, В.Е. Клочко, И. Пригожин и др.). Мы предлагаем рассматривать интернальность в качестве личностной характеристики способа обращения человека с неопределенностью и понимаем осуществление выбора как акт разрешения состояния неопределенности.

В соответствии с целью нашего исследования мы можем определить интернальность, как устойчивую тенденцию при взаимодействии человека с миром реализовывать в более или менее широком круге субъективно значимых жизненных ситуаций специфический принцип и личностную компетенцию, позволяющие ему самостоятельно наделять актуальную ситуацию качеством неопределенности и, непременно сохраняя субъектность, разрешать её (неопределенность) посредством осуществления выбора с опорой на внутренние силы, средства и ценностно-смысловые ориентиры поведения, т.е. личностного выбора по интернальному типу.

Таким образом, можно говорить о структурной сложности интернальности, о двух качественно различных, но взаимосвязанных уровнях реализации интернального поведения.

1. Динамическая тенденция, направленность, устремленность человека на взаимодействие с миром по интернальному типу и, соответственно, реализующие эту тенденцию (выступающие в качестве направляющих параметров) системные психологические процессы-регуляторы, которые «модулируют» образы восприятий, представлений и действий человека качеством интернальности, т.е. обеспечивают активное присутствие самого принципа интернальности (как метастратегии) в актуальном психическом и психологическом процессе и таким образом регулируют поведение («внутренний», регуляционный аспект).

2. Репертуарный комплекс психологических «инструментов» - качеств, способностей, специфических навыков, стереотипов, ценностных представлений, тактик, стратегий и способов поведения (что может быть выражено в понятии «личностная компетенция»), позволяющих человеку предметно реализовывать такую устремленность в более или менее широком круге жизненных ситуаций с большей или меньшей эффективностью («внешний», инструментально-операциональный аспект).

Интернальность, судя по истории изучения вопроса, формируется как результат обобщения (1) опыта восприятия и осознания человеком себя, своего поведения и собственных качеств как причин и условий возникновения тех или иных событий и обстоятельств в различных сферах жизни, (2) опыта переживания личностной значимости последствий и результатов собственной активности или её отсутствия, а также в целом (3) опыта непосредственной практики взаимодействия человека с миром. При этом интернальность имеет активное онтологическое основание в природе человеческой личности и связана с фундаментальными аспектами избирательности психического отражения.

Инструментально-операциональный аспект интернальности в настоящее время обстоятельно изучен в работах, посвященных проблематике 
выбора, принятия решений и поведения в ситуации неопределенности. Наиболее разработанные системы представлений в этом русле нацелены на изучение проблем самодетерминации (Д.А. Леонтьев и др.), психологии интеллектуально-личностной регуляции поведения в ситуации неопределенности (Т.В. Корнилова и др.) и психологии суверенности человека в теории психологических систем (В.Е. Клочко, О.М. Краснорядцева и др.).

Концепция личностного потенциала предложена Д.А. Леонтьевым и базируется на синтетической платформе психологической теории деятельности и разработках экзистенциальной и позитивной психологии. Личностный потенциал, согласно Д.А. Леонтьеву, это «интегральная характеристика уровня личностной зрелости, реализуемая в способности к автономной самодетерминации и представляемая как комплекс особенностей системной организации личности в целом, со сложной архитектоникой, основанной на сложной схеме опосредствования, позволяющей осуществлять деятельность в относительной свободе от заданных условий этой деятельности, как внешних, так и внутренних» [45. С. 3], а также «исходить из устойчивых внутренних критериев и ориентиров в своей жизнедеятельности, сохраняя стабильность смысловых ориентаций и эффективность деятельности на фоне давлений и изменяющихся внешних условий» [46. С. 91].

Другое ведущее направление комплексного изучения психологии поведения в ситуации неопределенности представлено работами исследовательской группы Т.В. Корниловой. Так, в коллективной монографии «Психология неопределенности: единство интеллектуально-личностного потенциала человека» [47], посвященной одному из направлений развития научной линии «смысловой теории мышления», представлены результаты цикла исследований функционирования динамических систем регуляции решений и выборов человека, раскрывающих классическую проблему единства интеллекта и аффекта на основе понимания человека как принимающего и преодолевающего условия неопределенности. В разработках данного направления устанавливается роль процессов принятия неопределенности как фокусирующих активность субъекта (от уровней самосознания личности до глубинной мотивации) в структурировании взаимодействий переменных интеллектуального и личностного потенциала человека.

Третье направление представлено работами представителей сибирской психологической школы в рамках теории психологических систем, являющейся парадигмальным развитием, прежде всего, учения о высших психических функциях и опосредствовании Л.С. Выготского [48]. Здесь в настоящее время во главу угла ставится проблема суверенности человека как высшего уровня становления личности, и на основе идеалов постнеклассической рациональности формируется методологическое пространство для рассмотрения соответствующих процессов суверенизации (Д.Ю. Дорофеев, С.К. Нартова-Бочавер, В.Е. Клочко, О.М. Краснорядцева и др.).

Соотнося понятие суверенности с понятиями автономии и самодетерминации личности, можно сказать, что последние центрированы на вопросе «интраиндивидуальной устойчивости человека», его ориентации на 
собственный закон развития как «меры функциональной способности (компетентности) личности преодолевать заданные внутренние и внешние условия, становясь полноценным субъектом собственной жизни в меняющемся мире» [49. С. 79]. Самодетерминация реализуется «в виде осознанного выбора способа действий, учитывающего как внутренние стремления, так и внешние условия жизни человека» [50. С. 7]. Таким образом, внимание исследователей личностной автономии сфокусировано в первую очередь на инструментально-операциональном аспекте интернальности.

Тем временем понятие «суверенность» предполагает представление о человеке как о сложной открытой саморазвивающейся системе, сущностным аспектом бытия которой являются не развитие, гомеостаз и постоянно преодолеваемое противоречие внутреннего и внешнего, а гомеорез, непрерывное «становление» и открытость [48]. «Категория суверенности позволяет ухватить способность человека к устойчивому самоизменению» [51. С. 67], отражает меру «устойчивости протяженного во времени процесса изменений» [52. С. 19] и «может быть понята как мера субъектности, характерная для данного человека, отражающая выраженность способности к продуктивному самоосуществлению» [51. С. 67]. Суверенность предполагает «овладение (человеком) собой как субъектом жизни и управление своей жизнью и своим развитием» [Там же]. Один из основных проблемных вопросов суверенности - «как удерживает тождественность самому себе... постоянно преобразующийся человек?» [53. С. 333] - оказывается непосредственно связанным с корнем феномена интернальности.

В каждом из рассмотренных направлений уделяется внимание регуляционному аспекту интернальности. В первом случае он рассматривается в экзистенциально-гуманистическом ключе через понятие о жизнестойкости (С. Мадди) и утверждение врожденной потребности в автономии (Э. Деси, Р. Райан), которая, однако, как отмечалось выше, определена эмпирически и не интегрирована в целостную общепсихологическую модель.

Во втором случае для объяснения регуляции поведения по интернальному типу акцентируются личностные качества и процессы, выраженные конструктом «принятие неопределенности», фокусирующие активность субъекта и позволяющие актуализировать при регуляции поведения глубинную мотивацию и продуктивно обрабатывать ситуацию выбора на верхних личностных уровнях (самосознание) при условии достаточной компетенции. Однако субъектная включенность и глубина личностной опосредствованности выборов здесь ставятся в зависимость исключительно от актуальных мотивационно-смысловых и ценностных доминант, присутствующих на уровнях бытийного, рефлексивного или духовного сознания личности. Внимание исследователей здесь сфокусировано на изучении процессуальных аспектов интеллектуально-личностной регуляции деятельности выбора, но в большей степени в связи с проблемами её продуктивности, нежели в связи с вопросами изучения онтологических оснований и психологических обстоятельств принципиальной возможности деятельности выбора. 
В третьем подходе даётся общее представление о силах, лежащих у основания самоорганизации, силах становления, соотносимых с «реальностью Духа» [44. С. 28], которые реализуются в ходе «жизнеосуществления» и конституируют в моментах соприкосновения субъективного и объективного чувственно-сверхчувственную смысловую реальность собственного жизненного мира человека и его «истинного тела» (термин В.Е. Клочко [48. С. 103]).

Таким образом, в теории психологических систем и в концепции личностного потенциала прослеживается указание на натуральную основу интернальности, однако остаются открытыми два класса вопросов, свидетельствующих о сохранении недостатка теоретического осмысления феномена интернальности (прежде всего в отношении регуляционного аспекта).

Во-первых, если принять, что тенденция к интернальному поведению имеет натуральную природу, то каков конкретный психологический смысл этого основания, каким образом его объективировать в дискурсе психологии личности? Что конкретно (феноменологически) может являться естественной движущей силой осуществления интернальной активности? В чем природосообразность и культурно-историческая полезность этого явления, какова его естественная причина, онтологическое основание?

Во-вторых, посредством каких действующих факторов интернальность (как онтологический принцип, императив сохранения субъектности) реализуется в психике и личности? Какого рода процессы в качестве управляющих параметров обеспечивают регуляцию взаимодействия человека с миром по интернальному типу, оказывают организующее влияние на формирование и применение психологического инструментария интернального поведения, в чем специфика такой регуляции? Какой психологический механизм сцепляет принцип интернальности и переживание реальной психологической структуры любой актуальной ситуации? От чего зависит широта психологической «иррадиации» принципа интернальности (как метастратегии) в личностной системе, в жизненном мире человека? Соответственно, могут ли процессы интернальности быть трансформированы искусственно, произвольно? Можно ли научить человека психотехническими методами целенаправленно расширять границы личностной интернальности, многомерный жизненный объем психологически освоенного мира?

Предложенная двухуровневая структурная модель и сформулированные вопросы позволяют операционализировать понятие интернальности и сформировать актуальное проблемное поле возможных направлений дальнейшего исследования психологии собственной активности человека и избирательности психического отражения.

Выводы. Понятие интернальности в настоящее время стоит в одном методологическом ряду среди таких центрированных на человеке психологических понятий, как собственно личность и её становление, ответственность, смысл, жизненная устойчивость, отношение, выбор и избирательность, субъектность, деятельность, самосознание, интенциональность, лич- 
ностный и интеллектуально-личностный потенциал, а также суверенность. Интернальность может выступать одним из ключевых понятий при изучении механизмов, сил и средств, через которые человек осуществляет интенциональное смысловое взаимодействие с жизненным миром, созидает и реализует своё «истинное тело» и «овладевает собственным поведением».

Интернальность является содержательно неоднородным понятием. В психологической литературе представлен ряд относительно самостоятельных концепций, формирующих теоретическое наполнение этого конструкта. Несмотря на детали различий в определении интернальности, суть феномена заключается в указании на психологическое содержание процессов и механизмов, при реализации которых причина и источник ключевых регулирующих влияний на происходящее связаны с собственной активностью человека как субъекта. Таким образом, локус контроля, уровень субъективного контроля, локус каузальности, интернальность ценностных и каузальных ориентаций - все эти понятия могут быть рассмотрены в качестве аспектов интернальности как особого психологического феномена.

Многочисленные психологические исследования свидетельствуют об обширных взаимосвязях различных форм проявления интернальности с широким кругом психологических и личностных характеристик, основными из которых являются когнитивная сложность, глубина и событийность субъективной временной перспективы и психологическая компетентность во времени, выраженная способность к смысловой регуляции поведения, развитая произвольность, ответственность, адаптивность и стрессоустойчивость. Интернальность является значимым условием эффективности внутренней деятельности личностного выбора и принципиально неотделима от феномена выбора, поскольку на поведенческом уровне проявляется исключительно в актах субъектной избирательной активности при разрешении ситуации неопределенности.

Интернальность может характеризовать как человека в целом, так и его личность в отношении различных сфер жизни. Эффективная личностная структура локусов интернальности может быть выраженно неравномерной (в континууме интернальный-экстернальный), что обусловлено факторами различной природы, в том числе ситуационными и социокультурными. В специфичных обстоятельствах структура локусов интернальности может оказываться не сбалансированной с фактическими личностными возможностями, в связи с чем связанная с интернальностью ответственность становится основанием для развития чрезмерного чувства вины и фактором риска общей психосоциальной дезадаптации, что принципиально компенсируется действием механизмов психологической защиты и развитием навыков конструктивного совладания с «тяжелыми» эмоциями - расширением интернальности в эмоциональной сфере.

Специфика осуществления человеком выбора по интернальному типу заключается в качественном своеобразии актуального функционирования личности, когда весь комплекс психологических феноменов, конституирующих процессы порождения и обращения с неопределенностью при 
осуществлении выбора, реализуется с сохранением человеком субъектности, интенциональности и чувства ответственности и с опорой на внутренние силы и средства поведения. Все это позволяет воспринимать интернальность как интегральную личностную характеристику способности человека к владению собственным поведением.

Целесообразно говорить об уровневом характере онтогенеза интернальности и рассматривать этот процесс в логике культурно-исторического развития высших психических функций, а также с учетом современных методологических представлений о личности как открытой психологической системе.

Проведенный теоретический анализ позволяет поставить проблемные вопросы о структурной сложности интернальности, о двух качественно различных, но взаимосвязанных уровнях реализации интернального поведения: (1) динамическая тенденция, направленность человека на взаимодействие с миром по интернальному типу (включая внутреннюю психологическую механику иррадиации и реализации этой тенденции в психологической системе, регуляционный аспект) и (2) репертуарный комплекс психологических «инструментов» - качеств, способностей, специфических навыков, стереотипов, ценностных представлений, тактик, стратегий и способов поведения (личностная компетенция), позволяющих человеку предметно реализовывать такую устремленность в более или менее широком круге жизненных ситуаций с большей или меньшей эффективностью (инструментальный аспект).

Если инструментальный аспект интернальности к настоящему времени изучен относительно подробно, то регуляционный аспект - природа и действующие факторы самой тенденции к интернальной активности остаётся актуальным проблемным полем для психологической теории. Разработка данных вопросов предполагает дальнейшее изучение личностных факторов осуществления человеком интернального выбора.

\section{Лuтература}

1. Выготский Л.С. Проблемы развития психики // Выготский Л.С. Собр. соч. : в 6 т. М. : Педагогика, 1983. Т. 3. С. 6-328.

2. Rotter J.B. Generalized expectancies for internal versus external control of reinforcement // Psychological Monographs. 1966. Vol. 80 (Whole № 609).

3. Хьелл Л., Зиглер Д. Теории личности. 3-е изд. СПб. : Питер, 2008. С. 376-391.

4. Weiner B., Kukla A. An attributional analysis of achievement motivation // Journal of Personality and Social Psychology. 1970. Vol. 15 (1). P. 1-20. doi:10.1037/h0029211

5. Рисмен Д. Некоторые типы характера и общество // Социологические исследования. 1993. № 7. С. 144-151.

6. Яницкий М.С., Серый А.В. Основные методологические подходы к изучению ценностно-смысловой сферы личности // Вестник Кемеровского государственного университета культуры и искусств. 2012. № 19-1. С. 82-97.

7. Бажин Е.Ф. Голынкина Е.А., Эткинд А.М. Метод исследования уровня субъективного контроля // Психологический журнал. 1984. Т. 5, № 3. С. 152-162. 
8. Бодалев А.А., Столин В.В., Аванесов В.С. Общая психодиагностика. СПб. : Речь, 2000. $440 \mathrm{c}$.

9. Современная психология мотивации / под ред. Д.А. Леонтьева. М. : Смысл, 2002. 343 с.

10. Выготский Л.С. Конкретная психология человека // Вестник Московского университета. Сер. 14, Психология. 1986. № 1. С. 52-65.

11. Бокова О.А. Особенности субъективного контроля у людей юношеского возраста с различной выраженностью личностной ригидности : автореф. дис. ... канд. психол. наук. Барнаул, 2002. 24 с.

12. Bieri J. Cognitive complexity-simplicity and predictive behavior // The Journal of Abnormal and Social Psychology. 1955. Vol. 51 (2). P. 263-268. doi:10.1037/h0043308

13. Серый А.В. Система личностных смыслов: структура, функции, динамика. Кемерово : Кузбассвузиздат, 2004. 272 с.

14. Thayer S., Gorman B.S., Wessman A.E., Schmeidler G., Mannucci E.G. The Relationship between Locus of Control and Temporal Experience // The Journal of Genetic Psychology. 1975. Vol. 126 (2). P. 275-279. doi:10.1080/00221325.1975.10532342

15. Леонтьев Д.А., Пилипко Н.В. Выбор как деятельность: личностные детерминанты и возможности формирования // Вопросы психологии. 1995. № 1. С. 97-110.

16. Серый А.В., Вечканова Е.М. Темпоральные аспекты актуализации смысловых граней субъективных образов переживания кризиса идентичности в период юности // Вестник Кемеровского государственного университета. 2015. Т. 3, № 3 (63). С. 238 247.

17. Ощепкова Г.И. Проявления экстернальности и интернальности при зависимом поведении // Филология и культура. 2015. № 3 (41). С. 333-336.

18. Муздыбаев К. Стратегии совладания с жизненными трудностями. Теоретический анализ // Журнал социологии и социальной антропологии. 1998. Т. 1, № 2. С. 37-47.

19. Шкуратова И.П., Анненкова Е.А. Личностные ресурсы как фактор совладания с кризисными ситуациями // Психология кризиса и кризисных состояний: междисциплинарный ежегодник. 2007. № 4. С. 17-23.

20. Бабич О.И., Терехова Т.А. Личностные ресурсы преодоления синдрома профессионального выгорания педагогов // Сибирский психологический журнал. 2009. № 31. C. $48-52$.

21. Реан А.А., Баранов А.А. Факторы стрессоустойчивости учителей // Вопросы психологии. 1997. № 1. С. 46-54.

22. Муздыбаев К. Переживание бедности как социальной неудачи: атрибуция ответственности, стратегии совладания и индикаторы депривации // Социологический журнал. 2001. № 1. С. 4-25.

23. Feather N.T. Valence of outcome and expectation of success in relation to task difficulty and perceived locus of control // Journal of Personality and Social Psychology. 1967. Vol. 7 (4, pt. 1). P. 372-386. doi:10.1037/h0025184

24. Нюттен Ж. Мотивация, действие и перспектива будущего / под ред. Д.А. Леонтьева. М. : Смысл, 2004. 608 с.

25. Муздыбаев К. Психология ответственности. Л. : Наука, 1983. 240 с.

26. Карась Д.В. Категориальное пространство интернализации личностного выбора // Вестник Томского государственного университета. 2010. № 331. С. 177-180.

27. Реан А.А. Психология изучения личности : учеб. пособие. СПб. : Изд. В.А. Михайлова, 1999. $288 \mathrm{c}$.

28. Шамионов Р.М. Психология социального поведения личности : учеб. пособие. Саратов : Наука, 2009. $186 \mathrm{c}$.

29. Холодная М.А. Психология интеллекта: парадоксы исследования. 2-е изд., перераб. и доп. СПб. : Питер, 2002. 272 с.

30. Мацумото Д. Психология и культура. СПб. : Прайм-Еврознак, 2002. 416 с.

31. Сартр Ж.-П. Экзистенциализм - это гуманизм // Сумерки богов. М. : Политиздат, 1989. C. 319-344. 
32. Ялом И. Экзистенциальная психотерапия. М. : Класс, 1999. С. 245.

33. Мэй Р. Сила и невинность: в поисках истоков насилия. М. : Смысл, 2001. 319 с.

34. Карась Д.В., Серый А.В. Постнеклассический взгляд на психологию выбора в терминах «отношение», «интенциональность» и «смысл» // Вестник психологии и педагогики Алтайского государственного университета. 2016. № 4. С. 100-112.

35. Реан А.А. Проблемы и перспективы развития концепции локуса контроля личности // Психологический журнал. 1998. № 4. С. 3-12.

36. Сатир В. Психотерапия семьи. СПб. : Речь, 2000. 281 с.

37. Бокова О.А. К вопросу о теоретических основах изучения психологических феноменов ответственности и локуса контроля // Мир науки, культуры, образования. 2014. № 5 (48). C. 181-183.

38. Серый А.В., Карась Д.В. Уровень напряженности защитных механизмов личности в зависимости от типа актуального смыслового состояния // Сибирский психологический журнал. 2007. № 25. С. 29-34.

39. Леонтьев Д.А. Психология смысла: природа, строение и динамика смысловой реальности. 2-е изд., испр. М. : Смысл, 2003. 487 с.

40. Карась Д.В., Миллер Н.А. Обусловленность выраженности эмпатии и чувствительности к отвержению при межличностном общении фактором актуального смыслового состояния // Студент и научно-технический прогресс : Психология материалы XLVIII Международной научной студенческой конференции. Новосибирск, 2010. C. $50-51$.

41. Леонтьев Д.А. Очерк психологии личности. М. : Смысл, 1993. С. 38-39.

42. Корнилова Т.В. Динамическое функционирование интеллектуально-личностного потенциала человека в психологической регуляции решений и выборов // Вестник Московского университета. Сер. 14, Психология. 2011. № 1. С. 67-78.

43. Корнилова Т.В. Неопределенность, выбор и интеллектуально-личностный потенциал человека // Методология и история психологии. 2009. № 4 (4). С. 47-59.

44. Галажинский Э.В., Клочко В.Е. Категория «отношение» в психологии в свете парадигмальной динамики науки // Мир психологии. 2011. № 4 (68). С. 14-31.

45. Личностный потенциал: структура и диагностика / под ред. Д.А. Леонтьева. М. : Смысл, 2011. 675 с.

46. Дергачева О.Е., Дорфман Л.Я., Леонтьев Д.А. Русскоязычная адаптация опросника каузальных ориентаций // Вестник Московского университета. Сер. 14, Психология. 2008. № 3. С. 91-106.

47. Корнилова Т.В., Чумакова М.А., Корнилов С.А., Новикова М.А. Психология неопределенности: единство интеллектуально-личностного потенциала человека. М. : Смысл, 2010. 334 с.

48. Клочко В.Е. Самоорганизация в психологических системах: проблемы становления ментального пространства личности (введение в трансспективный анализ). Томск : Том. гос. ун-т, 2005. 174 с.

49. Калитеевская Е.Р., Леонтьев Д.А., Осин Е.Н., Бородкина Н.И. Смысл, адаптация и самодетерминация у подростков // Вопросы психологии. 2007. № 2. С. 79.

50. Дергачева О.Е. Личностная автономия как предмет психологического исследования : автореф. дис. ... канд. психол. наук. М., 2005. С. 7.

51. Трофимова Ю.В. Суверенизация личности как предмет постнеклассической психологии // Известия Алтайского государственного университета. 2012. № 1 (2). С. 67.

52. Клочко В.Е., Галажинский Э.В. Психология инновационного поведения. Томск : Томский государственный университет, 2009. 240 с.

53. Клочко В.Е., Лукьянов О.В. Личностная идентичность и проблема устойчивости человека в меняющемся мире: системно-антропологический ракурс // Вестник Томского государственного университета. 2009. № 324. С. 333-336.

Поступила в редакичию 26.11.2016 г.; повторно 27.02.2017 г.; принята 02.05.2017 г. 


\section{Сведения об авторе:}

КАРАСЬ Дмитрий Викторович, научный сотрудник лаборатории моделирования управленческих технологий Научно-исследовательского институга комплексных проблем сердечно-сосудистых заболеваний (Кемерово, Россия). E-mail: dv.karas@gmail.com

THEORETICAL AND METHODOLOGICAL APPROACHES TO THE UNDERSTANDING OF INTERNALITY AS A PSYCHOLOGICAL PHENOMENON

Siberian journal of psychology, 2017, 64, 24 48. DOI: 10.17223/17267080/64/2

Karas' Dmitry V., Federal State Budgetary Institution Research Institute for Complex Issues of Cardiovascular Diseases (Kemerovo, Russian Federation). E-mail: dv.karas@gmail.com

Key words: personality; internality; locus of control; personal choice; uncertainty; subjectivity; responsibility; self-determination; sovereignty; personal regulation of behavior.

The concept of internality refers to the psychology of processes and mechanisms, performing which a person takes possession of his behavior when the cause of what is happening belongs to his own activity.

The purpose of the article is to reveal basic theoretical and methodological approaches to the understanding of internality and to formulate several problematic issues regarding the comprehension of this phenomenon.

Internality category is substantively incoherent; it contains a number of relatively independent concepts.

The main concepts are: locus of control, as a generalized experience of the control of reinforcements (J. Rotter), locus of causality, as the tendency to perceive events as reasons by persons own activity (F. Haider, B. Weiner), the concept of Self-reinforcement (A. Bandura), tendency to make decisions based on internal values and motivational orientation (B. Weiner, D. Riesman), the locus of causal orientations (in self-determination theory of E. Deci, R. Ryan).

Numerous studies indicate the sustainable relationships between various aspects of internality with the wide range of psychological characteristics: cognitive complexity, depth, eventfulness of subjective temporal perspective, overall personal temporal-competence, the ability of value-semantic regulation of behavior, developed voluntariness, responsibility, and adaptability. In addition, internality is an important factor of the effectiveness of the internal personal choice activity, as a complicated behavioral act of resolving situations of uncertainty.

Internality is being formed during a person's interaction with the world as a result of generalization of interaction experiences and depends on internal, social, and cultural factors.

The analysis allows us to talk about the internality as an integral personality characteristic, indicating the uniqueness of the flow of psychological phenomena which constitute the processes of active generation of uncertainty and its subjective, intentional and responsible resolving in the implementation of personal choice.

It is reasonable to pose a question regarding the structural complexity of internality including the issue of two levels of the internal behavior implementation: focus on the subjective attitude towards reality (regulating aspect) and personal competence, which allows realizing this direction in the various life situations with greater or lesser efficiency (instrumental aspect).

The instrumental aspect of internality (what and with what psychological means a person chooses while making a personal choice) was studied in some details. The regulating aspect (what is the nature and the factors of the current inclination to the internal activity) is a relevant question in the field of the psychological theory

\section{References}

1. Vygotskiy, L.S. (1983) Sobranie sochineniy: $v 6 t$. [Collected Works. In 6 vols]. Vol. 3. Moscow: Pedagogika. pp. 6-328. 
2. Rotter, J.B. (1966) Generalized expectancies for internal versus external control of reinforcement. Psychological Monographs. 80(1). pp. 1-28. DOI: 10.1037/h0092976

3. Hjell, L. \& Ziegler, D. (2008) Teorii lichnosti [Personality Theories]. 3rd ed. Translated from English by S. Melenevskaya, D. Viktorova. St. Petersburg: Piter. pp. 376-391.

4. Weiner, B. \& Kukla, A. (1970). An attributional analysis of achievement motivation. Journal of Personality and Social Psychology. 15(1). pp. 1-20. DOI: 10.1037/h0029211

5. Rismen, D. (1993) Nekotorye tipy kharaktera i obshchestvo [Some types of character and society]. Sotsiologicheskie issledovaniya - Sociological Studies. 7. pp. 144-151.

6. Yanitskiy, M.S. \& Seryy, A.V. (2012) Osnovnye metodologicheskie podkhody k izucheniyu tsennostno-smyslovoy sfery lichnosti [The main methodological approaches to the study of the personality's axiological sphere]. Vestnik Kemerovskogo gosudarstvennogo universiteta kul'tury i iskusstv - Bulletin of Kemerovo State University. 19-1. pp. 82-97.

7. Bazhin, E.F. Golynkina, E.A. \& Etkind, A.M. (1984) Metod issledovaniya urovnya sub"ektivnogo kontrolya [A method for investigating the level of subjective control]. Psikhologicheskiy zhurnal. 5(3). pp. 152-162.

8. Bodalev, A.A., Stolin, V.V. \& Avanesov, V.S. (2000) Obshchaya psikhodiagnostika [General psychodiagnosis]. St. Petersburg: Rech'.

9. Leontyev, D.A. (ed.) (2002) Sovremennaya psikhologiya motivatsii [Modern psychology of motivation]. Moscow: Smysl.

10. Vygotsky, L.S. (1986) Konkretnaya psikhologiya cheloveka [Specific human psychology]. Vestnik Moskovskogo universiteta. Ser. 14: Psikhologiya - Moscow University Herald. Series 14. Psychology. 1. pp. 52-65.

11. Bokova, O.A. (2002) Osobennosti sub"ektivnogo kontrolya u lyudey yunosheskogo vozrasta s razlichnoy vyrazhennost'yu lichnostnoy rigidnosti [Subjective control in adolescence with different personal rigidity]. Abstract of Psychology Cand. Diss. Barnaul.

12. Bieri, J. (1955) Cognitive complexity-simplicity and predictive behavior. The Journal of Abnormal and Social Psychology. 51(2). pp. 263-268. DOI: 10.1037/h0043308

13. Seryy, A.V. (2004) Sistema lichnostnykh smyslov: struktura, funktsii, dinamika [The System of Personal Meanings: Structure, Functions, Dynamics]. Kemerovo: Kuzbassvuzizdat.

14. Thayer, S., Gorman, B.S., Wessman, A.E., Schmeidler, G. \& Mannucci, E.G. (1975) The Relationship between Locus of Control and Temporal Experience. The Journal of Genetic Psychology. 126(2). pp. 275-279. DOI: 10.1080/00221325.1975.10532342

15. Leontyev, D.A.\& Pilipko, N.V. (1995) Vybor kak deyatel'nost': lichnostnye determinanty i vozmozhnosti formirovaniya [Choice as activity: Personal determinants and possibilities of formation]. Voprosy psikhologii. 1. pp. 97-110.

16. Seryy, A.V. \& Vechkanova, E.M. (2015) Temporal aspects of the actualisation of the semantic facets of subjective images in the experience of identity crisis during adolescence. Vestnik Kemerovskogo gosudarstvennogo universiteta kul'tury i iskusstv - Bulletin of Kemerovo State University. 3(63). pp. 238-247. (In Russian). DOI: 10.21603/20788975-2015-3-238-247

17. Oshchepkova, G.I. (2015) Proyavleniya eksternal'nosti i internal'nosti pri zavisimom povedenii [Manifestations of externality and internality under dependent conduc]. Filologiya $i$ kul'tura - Philology and Culture. 3(41). pp. 333-336.

18. Muzdybaev, K. (1998) Strategii sovladaniya s zhiznennymi trudnostyami. Teoreticheskiy analiz [Strategies for coping with life's difficulties. Theoretical analysis]. Zhurnal sotsiologii i sotsial'noy antropologii - The Journal of Sociology and Social Anthropology. 1(2). pp. 37-47.

19. Shkuratova, I.P. \& Annenkova, E.A. (2007) Lichnostnye resursy kak faktor sovladaniya s krizisnymi situatsiyami [Personal resources as a factor in coping with crisis]. Psikhologiya krizisa i krizisnykh sostoyaniy. 4. pp. 17-23.

20. Babich, O.I. \& Terekhova, T.A. (2009) Personal resources of overcoming the teachers' professional stagnation syndrome. Sibirskiy psikhologicheskiy zhurnal - Siberian Journal of Psychology. 31. pp. 48-52. (In Russian). 
21. Rean, A.A. \& Baranov, A.A. (1997) Faktory stressoustoychivosti uchiteley [Teachers' stress resistance factors]. Voprosy psikhologii. 1. pp. 46-54.

22. Muzdybaev, K. (2001) Perezhivanie bednosti kak sotsial'noy neudachi: atributsiya otvetstvennosti, strategii sovladaniya i indikatory deprivatsii [Poverty as a social failure: Attribution of responsibility, coping strategies and indicators of deprivation]. Sotsiologicheskiy zhurnal - Sociological Journal. 1. pp. 4-25.

23. Feather, N.T. (1967) Valence of outcome and expectation of success in relation to task difficulty and perceived locus of control. Journal of Personality and Social Psychology. 7(4/1). pp. 372-386. DOI: $10.1037 / \mathrm{h} 0025184$

24. Nutten, J. (2004) Motivatsiya, deystvie i perspektiva budushchego [Motivation, action and the prospect of the future]. Translated from French by E. Pyataeva, N. Tolstykh, V. Shevyakhova. Moscow: Smysl.

25. Muzdybaev, K. (1983) Psikhologiya otvetstvennosti [Psychology of Responsibility]. Leningrad: Nauka.

26. Karas, D.V. (2010) Kategorial'noe prostranstvo internalizatsii lichnostnogo vybora [Categorial space of internalisation of personal choice]. Vestnik Tomskogo gosudarstvennogo universiteta - Tomsk State University Journal. 331. pp. 177-180.

27. Rean, A.A. (1999) Psikhologiya izucheniya lichnosti [Psychology of personality studies]. St. Petersburg: V.A. Mikhaylov.

28. Shamionov, R.M. (2009) Psikhologiya sotsial'nogo povedeniya lichnosti [Psychology of social behavior of the individual]. Saratov: Nauka.

29. Kholodnaya, M.A. (2002) Psikhologiya intellekta: Paradoksy issledovaniya [Psychology of Intellect: Paradoxes of Research]. 2nd ed. St. Petersburg: Piter.

30. Matsumoto, D. (ed.) (2002) Psikhologiya i kul'tura [Culture and Psychology]. Translated from English by T. Gutman. St. Petersburg: Praym-Evroznak.

31. Sartre, J.-P. (1989) Ekzistentsializm - eto gumanizm [Existentialism is humanism]. In: Nietzsche, F. et al. Sumerki bogov [Twilight of the Gods]. Moscow: Politizdat. pp. 319-344.

32. Yalom, I. (1999) Ekzistentsial'naya psikhoterapiya [Existential psychotherapy]. Translated from English by T. Drabkina. Moscow: Klass. pp. 245.

33. May, R. (2001) Sila i nevinnost': v poiskakh istokov nasiliya [Power and Innocence: In Search of the Sources of Violence]. Translated from English by A. Ponogrebsky. Moscow: Smysl.

34. Karas, D.V. \& Seryy, A.V. (2016) Postnonclassical view of the psychology of choice in the terms of "attitude", "intentionality" and "meaning". Vestnik psikhologii i pedagogiki Altayskogo gosudarstvennogo universiteta. 4. pp. 100-112. (In Russian).

35. Rean, A.A. (1998) Problemy i perspektivy razvitiya kontseptsii lokusa kontrolya lichnosti [Problems and perspectives of the development of the concept of personality control locus]. Psikhologicheskiy zhurnal. 4. pp. 3-12.

36. Satir, V. (2000) Psikhoterapiya sem'i [Family Psychotherapy]. Translated from english by I. Avidon, O. Isakova. St. Petersburg: Rech'.

37. Bokova, O.A. (2014) K voprosu o teoreticheskikh osnovakh izucheniya psikhologicheskikh fenomenov otvetstvennosti i lokusa kontrolya [On theoretical foundations of the study of psychological phenomena of responsibility and the locus of control]. Mir nauki, kul'tury, obrazovaniya. 5(48). pp. 181-183.

38. Seryy, A.B. \& Karas, D.V. (2007) Uroven' napryazhennosti zashchitnykh mekhanizmov lichnosti v zavisimosti ot tipa aktual'nogo smyslovogo sostoyaniya [The level of tension of the individual's defense mechanisms, depending on the type of the actual semantic state]. Sibirskiy psikhologicheskiy zhurnal Siberian Journal of Psychology. 25. pp. 29-34.

39. Leontyev, D.A. (2003) Psikhologiya smysla: priroda, stroenie $i$ dinamika smyslovoy real'nosti [Psychology of meaning: nature, structure and dynamics of meaningful reality]. 2nd ed. Moscow: Smysl.

40. Karas, D.V. \& Miller, N.A. (2010) [Expression of empathy and sensitivity to rejection in interpersonal communication conditioned by actual semantic state]. Student $i$ nauchno- 
tekhnicheskiy progress [Student and Scientific Progress]. Proc. of the 48th International Conference. Novosibirsk. pp. 50-51. (In Russian).

41. Leontyev, D.A. (1993) Ocherk psikhologii lichnosti [Essay on the psychology of personality]. Moscow: Smysl. pp. 38-39.

42. Kornilova, T.V. (2011) Dinamicheskoe funktsionirovanie intellektual'no-lichnostnogo potentsiala cheloveka $\mathrm{v}$ psikhologicheskoy regulyatsii resheniy i vyborov [Dynamic functioning of the person's intellectual and personal potential in the psychological regulation of decisions and elections]. Vestnik Moskovskogo universiteta. Seriya 14: PsikhologiyaMoscow University Herald. Series 14. Psychology. 1. pp. 67-78.

43. Kornilova, T.V. (2009) Neopredelennost', vybor i intellektual'no-lichnostnyy potentsial cheloveka [Uncertainty, choice and intellectual and personal potential of a person]. Metodologiya $i$ istoriya psikhologii-Methodology and History of Psychology. 4(4). pp. 47-59.

44. Galazhinsky, E.V. \& Klochko, V.E. (2011) Kategoriya "otnoshenie" v psikhologii v svete paradigmal'noy dinamiki nauki [The category of "attitude" in psychology in terms of paradigmal dynamics of science]. Mir psikhologii. 4(68). pp. 14-31.

45. Leontyev, D.A. (ed.) (2011) Lichnostnyy potentsial: struktura i diagnostika [Personality Potential: Structure and Siagnostics]. Moscow: Smysl.

46. Dergacheva, O.E., Dorfman, L.Ya. \& Leontyev, D.A. (2008) Russkoyazychnaya adaptatsiya oprosnika kauzal'nykh orientatsiy [Russian-language adaptation of the questionnaire of causal orientations]. Vestnik Moskovskogo universiteta. Seriya 14: PsikhologiyaMoscow University Herald. Series 14. Psychology. 3. pp. 91-106.

47. Kornilova, T.V., Chumakova, M.A., Kornilov, S.A. \& Novikova, M.A. (2010) Psikhologiya neopredelennosti: edinstvo intellektual'no-lichnostnogo potentsiala chelove$k a$ [Psychology of uncertainty: The unity of the person's intellectual and personal potential]. Moscow: Smysl.

48. Klochko, V.E. (2005) Samoorganizatsiya v psikhologicheskikh sistemakh: problemy stanovleniya mental'nogo prostranstva lichnosti (vvedenie v transspektivnyy analiz) [Selforganisation in psychological systems: Problems of individual mental space formation (introduction to transspective analysis)]. Tomsk: Tomsk State University.

49. Kaliteevskaya, E.R., Leontyev, D.A., Osin, E.N. \& Borodkina, N.I. (2007) Smysl, adaptatsiya i samodeterminatsiya u podrostkov [Sense, adaptation and self-determination in adolescents]. Voprosy psikhologii. 2. pp. 79.

50. Dergacheva, O.E. (2005) Lichnostnaya avtonomiya kak predmet psikhologicheskogo issledovaniya [Personal autonomy as a subject of psychological research]. Abstract of Psychology Cand. Diss. Moscow. pp. 7.

51. Trofimova, Yu.V. (2012) Personal sovereignisation as an object of post-nonclassical psychology. Izvestiya Altayskogo gosudarstvennogo universiteta - Altai State University Journal. 1(2). pp. 67. (In Russian).

52. Klochko, V.E. \& Galazhinskiy, E.V. (2009) Psikhologiya innovatsionnogo povedeniya [Psychology of innovative behavior]. Tomsk: Tomsk State University.

53. Klochko, V.E. \& Lukyanov, O.V. (2009) Personality identity and the problem of personal steadiness in the changing world: System and anthropological approach. Vestnik Tomskogo gosudarstvennogo universiteta - Tomsk State University Journal. 324. pp. 333-336. (In Russian).

Received 26.11.2016;

Revised 27.02.2017;

Accepted 02.05.2017 